OPEN ACCESS

Edited by:

Tobias Hayer

University of Bremen, Germany

Reviewed by:

Natale Canale,

University of Padova, Italy

Ruth Elisabeth Von Brachel,

Ruhr University Bochum, Germany

*Correspondence:

Isabelle Giroux

isabelle.giroux@psy.ulaval.ca

Specialty section:

This article was submitted to

Psychopathology,

a section of the journal

Frontiers in Psychology

Received: 31 January 2017

Accepted: 23 May 2017

Published: 09 June 2017

Citation:

Giroux I, Goulet A, Mercier J, Jacques $C$ and Bouchard S (2017) Online and Mobile Interventions for

Problem Gambling, Alcohol, and

Drugs: A Systematic Review.

Front. Psychol. 8:954.

doi: 10.3389/fpsyg.2017.00954

\section{Online and Mobile Interventions for Problem Gambling, Alcohol, and Drugs: A Systematic Review}

\author{
Isabelle Giroux ${ }^{1 *}$, Annie Goulet ${ }^{1}$, Jonathan Mercier ${ }^{1}$, Christian Jacques ${ }^{1}$ and \\ Stéphane Bouchard ${ }^{2}$ \\ ${ }^{1}$ Centre québécois d'excellence pour la prévention et le traitement du jeu, Université Laval, Québec, QC, Canada, \\ ${ }^{2}$ Cyberpsychology Laboratory of UQO, Université de Québec en Outaouais, Gatineau, QC, Canada
}

Online interventions for gambling, alcohol, and illegal drug related problems have been developing at a fast pace over the past decade. Yet, little is known about the content and efficacy of interventions provided entirely online for reducing drug/alcohol use and gambling, or about the characteristics of those who use these interventions. This systematic review aims to describe the characteristics of online interventions, their efficacy, and the profile of their clientele. Documentation was mainly obtained through four scientific databases in psychology, technology, and medical research (PsychINFO, MedLine, Francis, and INSPEC) using three keywords (substances or gambling, intervention, Internet). Of the 4,708 documents initially identified, 18 studies meeting admissibility criteria were retained and analyzed after exclusion of duplicates and non-relevant documents. No study in the review related to problem gambling. The majority of interventions were based upon motivational or cognitive-behavioral theoretical approaches and called upon well-established therapeutic components in the field of addictions. The participants in these studies were generally adults between 30 and 46 years old with a high school education and presenting a high risk or problematic use. More than three quarters of the studies showed a short-term decrease in use that was maintained 6 months later, but only two studies included a 12 months follow-up. Online interventions seem promising and appear to meet the needs of participants who are in the workforce and seeking help for the first time. Long-term efficacy studies should nonetheless be conducted.

Keywords: psychological intervention, Internet, mobile application, addiction, drug, alcohol, gambling

\section{INTRODUCTION}

Substance use disorder, including alcohol and different classes of drugs, can be defined as a group of cognitive, behavioral, and physiological symptoms indicating that an individual continues using the substance despite significant substance-related problems (American Psychiatric Association, 2013). Gambling behaviors activate reward systems similar to those activated by drugs and produce symptoms comparable to those produced by the substance use disorders (American Psychiatric Association, 2013), and Gambling disorder is the only behavioral addiction with sufficient research to be included in the Substance-related and addictive disorders category of the Diagnostic and Statistical Manual of Mental Disorders (5th Edn.; DSM-5; American Psychiatric Association, 2013). 
Systematic reviews of literature report 1 year prevalence rates of $6.6 \%$ for alcohol use disorders, $2.4 \%$ for other substance use disorders (Somers et al., 2004), and wide variations in past-year problem gambling rates across different countries (0.12-5.8\%; Calado and Griffiths, 2016).

Initiating and complying with treatment can be a challenge for clienteles presenting alcohol, drug, or gambling-related problems. In order to overcome the obstacles inherent to psychological interventions and to reduce costs associated with addictions and non-consultation (Sacks et al., 2015), online, and mobile application interventions are developing at a fast pace (Lal and Adair, 2014). What content do they offer to users? Are they effective for reducing drug/alcohol use and gambling? Who is participating in this type of treatment? This systematic review will help to answer these questions.

Even though several psychosocial interventions have shown their efficacy for treating drug, alcohol (Dutra et al., 2008; Magill and Ray, 2009), and gambling disorders (Pallesen et al., 2005; Gooding and Tarrier, 2009), help-seeking rates are low. Only $36 \%$ of problem drinkers (Cunningham and Brelin, 2004) and $18 \%$ of problem gamblers seek formal assistance (Suurvali et al., 2008). Several obstacles curb help-seeking: need for anonymity or autonomy, shame, and denial (Suurvali et al., 2009; Priester et al., 2016), as well as limited availability (Rockloff and Schofield, 2004) or accessibility of interventions (i.e., scheduling conflicts, transportation difficulties; Clarke, 2007; Priester et al., 2016).

Self-help interventions could help circumvent these obstacles. These interventions are based on self-directed consultation of workbooks which include readings, useful tips and exercises that can be completed at home (Mains and Scogin, 2003; Swan and Hodgins, 2015; Andersson et al., 2016). Based on cognitivebehavioral and motivational approaches (Schmidt and Wykes, 2012; Swan and Hodgins, 2015), self-help interventions may be combined with telephone support provided by a therapist (Mains and Scogin, 2003; Swan and Hodgins, 2015). Several selfhelp interventions have demonstrated their benefits for treating problem gambling (Labrie et al., 2012; Giroux et al., 2015) and substance use (Carroll et al., 2008; Newman et al., 2011).

Offering self-help material online is a popular alternative in the Internet era. These online interventions first appeared in the 1990s (Childress and Asamen, 1998) and research on the topic multiplied between 2007 and 2010 (Lal and Adair, 2014). According to the findings of two systematic reviews, cognitive-behavioral interventions via computer for various mental health disorders (i.e., depression and anxiety) show an efficacy similar to that of standard face-to-face treatments (Barak et al., 2008) and present a better cost-efficacy ratio (Musiat and Tarrier, 2014). Considering the accessibility of the Internet and the growing popularity of mobile applications, online intervention for substance or gambling disorder could counteract several obstacles related to traditional "offline" services. On-line interventions have the potential to cover large areas at low costs and reach populations that are harder to reach (Barak et al., 2008).

To date, systematic reviews and meta-analyses that targeted the efficacy of online interventions for alcohol, drug, and gambling related problems included several self-help intervention formats (online, telephone, CDRoM, bibliotherapy), delivered alone or in combination, without necessarily differentiating them (for example, Tait and Christensen, 2010; McKellar et al., 2012; Tait et al., 2013; Danielsson et al., 2014; Takano et al., 2015). As such, these studies draw conclusions from a substantial heterogeneity of interventions. Moreover, the inclusion of different types of psychosocial interventions, including preventive interventions, hinders specific observations about interventions targeting the online psychological treatment of addictions. In addition, the participants of these studies have heterogeneous alcohol/drug use and gambling habits; ranging from abstinent, recreational and non-problem users, to those presenting a risk or disorder related to alcohol/drug use or gambling (for example, Tait and Christensen, 2010; Tait et al., 2013). These different participant groups surely have different motivations for signing up for an online intervention program, thus potentially biasing conclusions drawn about the efficacy of these interventions.

Indeed, syntheses on self-help online interventions for addiction do not give a full profile of users participating in online intervention efficacy studies. This information is relevant since these interventions may potentially attract individuals who are not interested in standard interventions (McKellar et al., 2012). For example, Cunningham et al. (2011) showed that at risk alcohol users who completed an online intervention were older, used the Internet more often, and consumed less alcohol during episodes of heavy drinking as compared to those who dropped out of the program. Postel et al. (2011) observed that alcohol users who registered for an online treatment were in greater proportion women, older, more educated, and more likely to be employed and seek treatment for the first time, as compared to those who used a standard treatment.

A literature review pertaining only to online psychological interventions and only to individuals who wish to modify their alcohol, drug, or gambling behavior will help clarify the current state of findings on these interventions. Indeed, a review would shed light on the efficacy of online treatment for drug, alcohol, and gambling problems, and help identify areas of research that need further investigation. Given the diversity of online interventions and technologies developed in recent years, the timing seems appropriate to collect and analyze current available research data. In short, such a review is a step toward better informing public decision-makers, stakeholders and researchers who want to look into new technologies to improve and increase accessibility and adherence to treatments.

The goal of this systematic review is to summarize current knowledge regarding psychological interventions provided entirely online (via computers or mobile applications) for at risk or problem gamblers or users (alcohol, illegal drugs) and that were assessed for efficacy. This review aims to: (a) identify the objectives of the interventions; (b) describe their characteristics (theoretical approach, main components) and modalities (duration, frequency); (c) report the efficacy of interventions in reducing alcohol/drug use and gambling; (d) shed light on participant characteristics; and (e) report the methodological quality of the studies. 


\section{MATERIALS AND METHODS}

\section{Research Strategies}

Studies relating to online treatment of alcohol, drug (excluding prescribed medication) or gambling related problems were identified via the PsycINFO, MedLine, Francis, and INSPEC databases. Two research strategies were used. First, all databanks were searched with three groups of keywords within the entire text:

(gambl* OR "substance misuse" OR "substance abuse" OR "substance addic*" OR "substance dependence" OR "substance related disorder" OR "drug abuse" OR "drug misuse" OR "drug addic*” OR "drug dependence" OR "alcohol abuse" OR "alcohol misuse" OR "alcohol addic*” OR "alcohol dependence") AND (online OR app OR apps OR computer* OR smartphone* OR "mobile phone*" OR virtual OR "mobile device*") AND (treatment* OR intervention* OR therap* OR "online therap*" OR "online intervention*")

Second, PsycINFO database thesaurus and its equivalent in MedLine-the "MESH terms" were used. The group of keywords for the PsycINFO database was:

(\{Alcohol Abuse $\}$ OR \{Alcoholism $\}$ OR \{Drug Abuse $\}$ OR \{Drug Addiction\} OR \{Gambling\} AND (\{Computer Assisted Therapy\} OR \{Online Therapy\})

For the MedLine database, the group of "Mesh terms" was the following:

("Gambling”[Mesh]) OR "Substance-Related Disorders" [Mesh]) AND (“Therapy, Computer-Assisted”[Mesh]) OR “Drug Therapy, Computer-Assisted”[Mesh])

A search conducted on the http://www.clinicaltrial.org site made it possible to obtain references for unpublished studies and to contact their authors when inclusion criteria were met.

\section{Inclusion and Exclusion Criteria}

Studies meeting the following criteria were included: (1) written in English or French, (2) published between January 1991 and June 2015 inclusively, (3) involving at least one group whose intervention was entirely online, (4) the intervention targeted the reduction of behaviors or symptoms related to alcohol, drug use, or gambling (5) conducted with users (vs. non-users/abstinents), and (6) used a research design.

Studies were excluded if: (1) the online computer support was used for promoting awareness, prevention (i.e., personalized feedback) or strictly for evaluation, (2) the interventions only targeted relapse prevention or consolidation, and (3) they did not include efficacy data.

\section{Article Selection Procedure}

Four thousand, seven hundred and eight studies were initially identified, from which 1,204 duplicates were withdrawn. The titles and abstracts of the remaining 3,504 studies were read and 3,220 non-relevant studies were excluded. Upon the second selection round, 284 studies were fully read to verify inclusion and exclusion criteria. The second selection was the subject of an interrater agreement between two evaluators. The evaluators agreed on criteria for $69.3 \%$ of the studies, which was considered unsatisfactory. After clarifying the criteria, the evaluators similarly classified $90.3 \%$ of the studies, a satisfactory percentage (Lombard et al., 2002). Disagreements were discussed until consensus was reached. Upon completion of the article selection, 18 studies were retained for analysis. Figure 1 depicts the search process.

\section{Methodological Quality of the Studies}

The methodological quality of the studies was evaluated using a list of 11 criteria recommended by the Cochrane Back Review Group (Berger and Alperson, 2009). For a study to be judged as possessing good methodological quality, a minimal threshold of six out of the 11 criteria must be met (Berger and Alperson, 2009). The evaluation scale for each criterion is as follows: Yes $(+)$, No (-) or I don't know (?). Since four criteria were not applicable within the context of this review, only seven of the proposed criteria were retained and rated. The more a study obtains positive ratings, the more it possesses methodological elements of good quality.

\section{Data Analysis}

An extraction grid was developed and filled for each study. The information was collected based on eight themes: (1) type

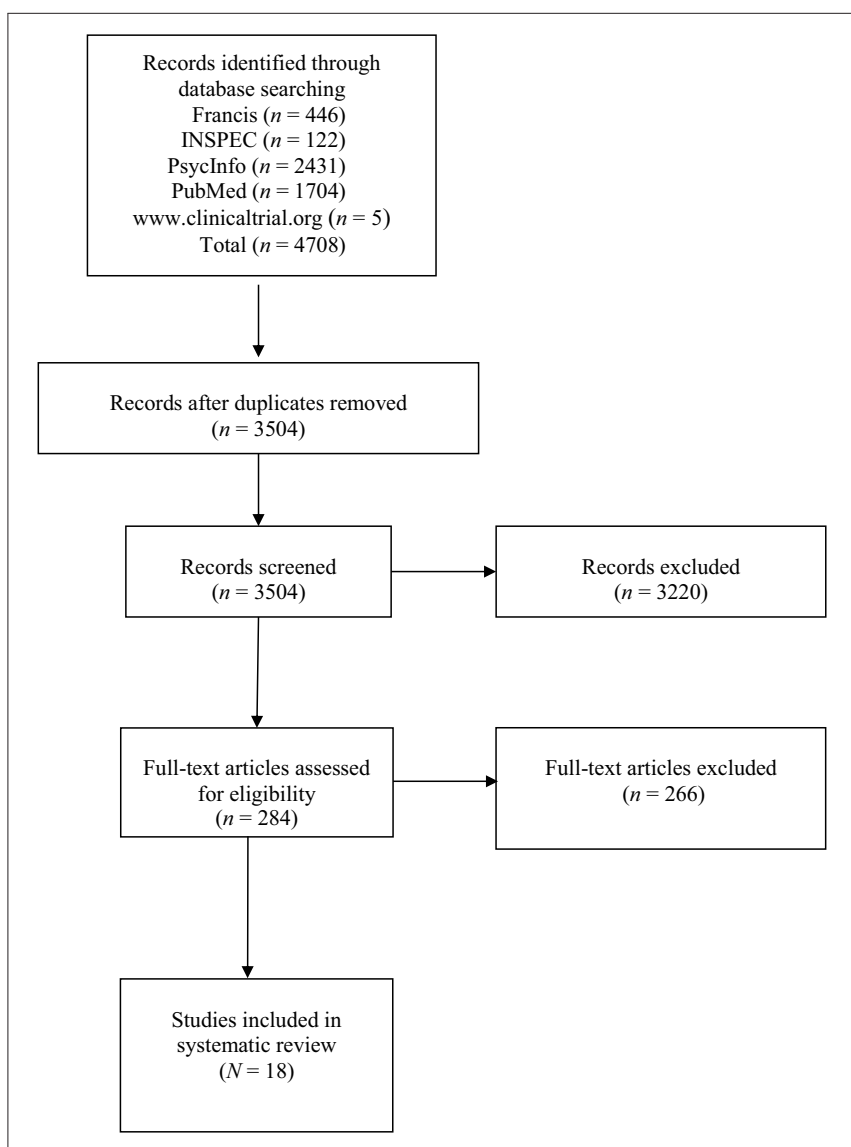

FIGURE 1 | Flow chart displaying the literature search process. 
of study, (2) methodology, (3) description of participants, (4) intervention objectives, (5) main findings, (7) conclusion, and (8) methodological quality.

The study coordinator and five psychology doctoral students participated in data extraction. An undergraduate research assistant counter-verified the information extracted for the 18 studies.

\section{RESULTS}

\section{Description of Online Interventions}

To facilitate the reading of the Results section, the 18 studies are referenced using exponents (see Table $\mathbf{1}$ ).

Eighteen studies were included in the review and these studies evaluated 22 different interventions in total. Fifteen studies $^{1}$ to 15 evaluated 19 interventions for alcohol use. As shown in Table 1, 19 interventions are presented for alcohol use since five studies $1,5,7,9,15$ compared the efficacy of two interventions and two studies ${ }^{12,13}$ evaluated the same intervention. The three remaining studies ${ }^{16,17,18}$ evaluated an intervention relating to drug use (two for cannabis ${ }^{16,18}$ and one for cocaine ${ }^{17}$ ). No study in the review related to problem gambling.

Three of the 22 interventions ${ }^{7,8}$ are mobile applications for alcohol use, while the others are online interventions $(86.4 \%$; 1 to 6,9 to 18 ).

\section{Theoretical Models and Therapeutic Objectives}

Thirteen interventions were based, at least in part, upon the cognitive and/or behavioral model (59.1\%; $1,3,4,6,8,9,11,12,14,16,17)$, nine upon a motivational approach $1,4,6,9,11,14,17$, three upon a solution-focused approach $^{15,18}$, and three upon a relapse prevention model ${ }^{6,15,17}$. Self-regulation theories ${ }^{3,4,12,17}$ and planned behavior ${ }^{7}$ underpin $^{2}$ certain interventions, whereas for four interventions ${ }^{2,5,10}$, the theoretical approaches were not indicated.

Of the 22 interventions, $14(63.6 \% ; 1$ to 3,5 to $7,9,10,12,15)$ targeted decreasing use, seven ${ }^{4,8}, 11,14,16$ to 18 offered the choice between decreasing use and abstinence, and only one ${ }^{9}$ targeted abstinence.

\section{Techniques and Interventions}

The majority of interventions (90.9\%; 1 to 6,8 to 18 ) used standard self-help therapeutic material: self-report assessment, self-recordings of use, exercises, readings, and videos. This material aimed, for example, to help the individuals identify at risk situations, determine their goals, modify their thoughts, develop problem solving and emotion management strategies, and to prevent relapse. In addition to this material, four interventions $1,9,11,18$ included online chatting with a clinician, and only one $\mathrm{e}^{1}$ involved participating in a discussion forum.

Two interventions via mobile applications differed from the other interventions $\left(9.1 \% ;{ }^{7}\right)$; the Check your BAC and PartyPlanner App programs. These interventions enabled users to plan and simulate their alcohol use for a given event and receive an estimate of their blood alcohol levels in real-time.

\section{Intensity}

Table 1 describes the intensity of the interventions in terms of total duration, frequency of use and completion time. For three interventions $\left(13.6 \% ;{ }^{2,5,15}\right)$, users' online participation was required only once or twice, whereas the other online interventions lasted between 1 week and 6 months, with suggested utilization of variable frequency (for example, $6,7,9,10,14,16,17$ ).

\section{Profile of the Online Intervention Participants}

The sample characteristics for each of the studies are shown in Table 2. A description of the participants is provided for 13 of the 18 studies: For the five other studies, the participants were recruited according to their distinctive characteristics; university students $^{2,5,7}$, military personnel returning from combat ${ }^{4}$ and workers from a certain workplace ${ }^{10}$. These studies were excluded from the general description that follows, but are presented in the targeted clientele section.

\section{Sex and Age}

Thirteen studies reported participants' sex. Six of them showed a similar distribution between men and women (46.2\%; $1,8,11$ to 14 ), however, a greater proportion of men was found in six studies $(46.2 \%$; $3,6,15$ to 18$)$, of which three evaluated an intervention for drug use ${ }^{16}$ to 18 . The mean age of the participants from the 12 studies varied between 30 and 46 years $1,3,6,8,9,11$ to 17 .

\section{Education}

Three studies did not provide information about education level $3,14,16$. Ten studies provided information on level of education, among which eight reported post-secondary studies for $50 \%, 8,11,12,13,17,18$ to $90 \%^{1}$ of the participants.

\section{Occupational Status}

Six of the 13 studies $(46.2 \% ; 1,6,8,11,12,13)$ indicated occupational status and showed that between 55 and $82 \%$ of participants were employed.

\section{Civil Status}

Four studies indicated civil status $(30.8 \% ; 6,8,12,13)$; the proportion of participants in a relationship varied between 35 and $61 \%^{13}$.

\section{Prior Treatment}

Four studies $(30.8 \%$; $11,12,13,17)$ reported previous treatment, with percentages varying between 4 and $24 \%$ of the sample.

\section{Drug/Alcohol Use Problem Severity}

The majority of the interventions from the 13 studies $(92.3 \%$; $1,3,6,8,9,11$ to 14,16 to 18 ) were applied to individuals with highrisk use or addiction. 


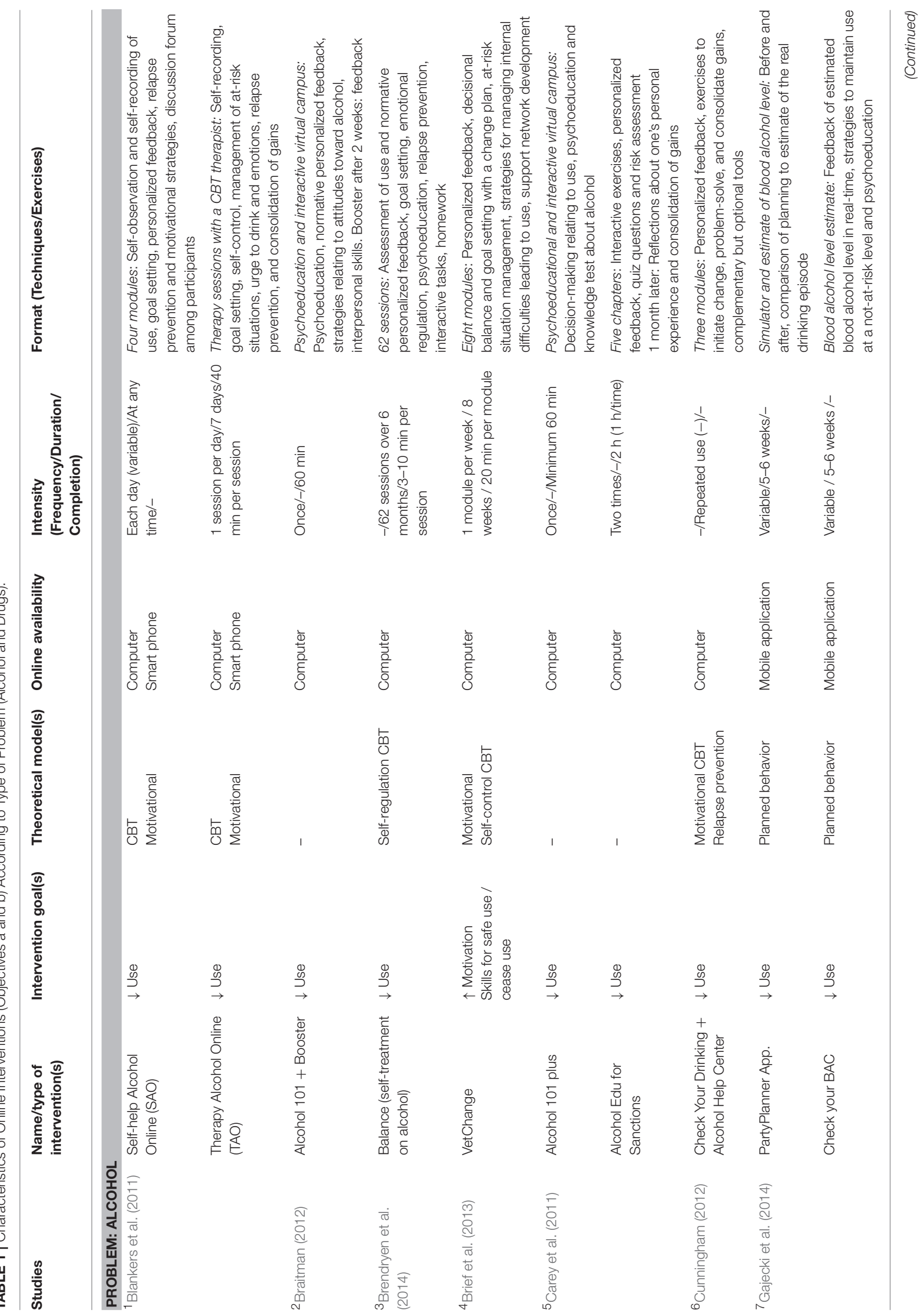




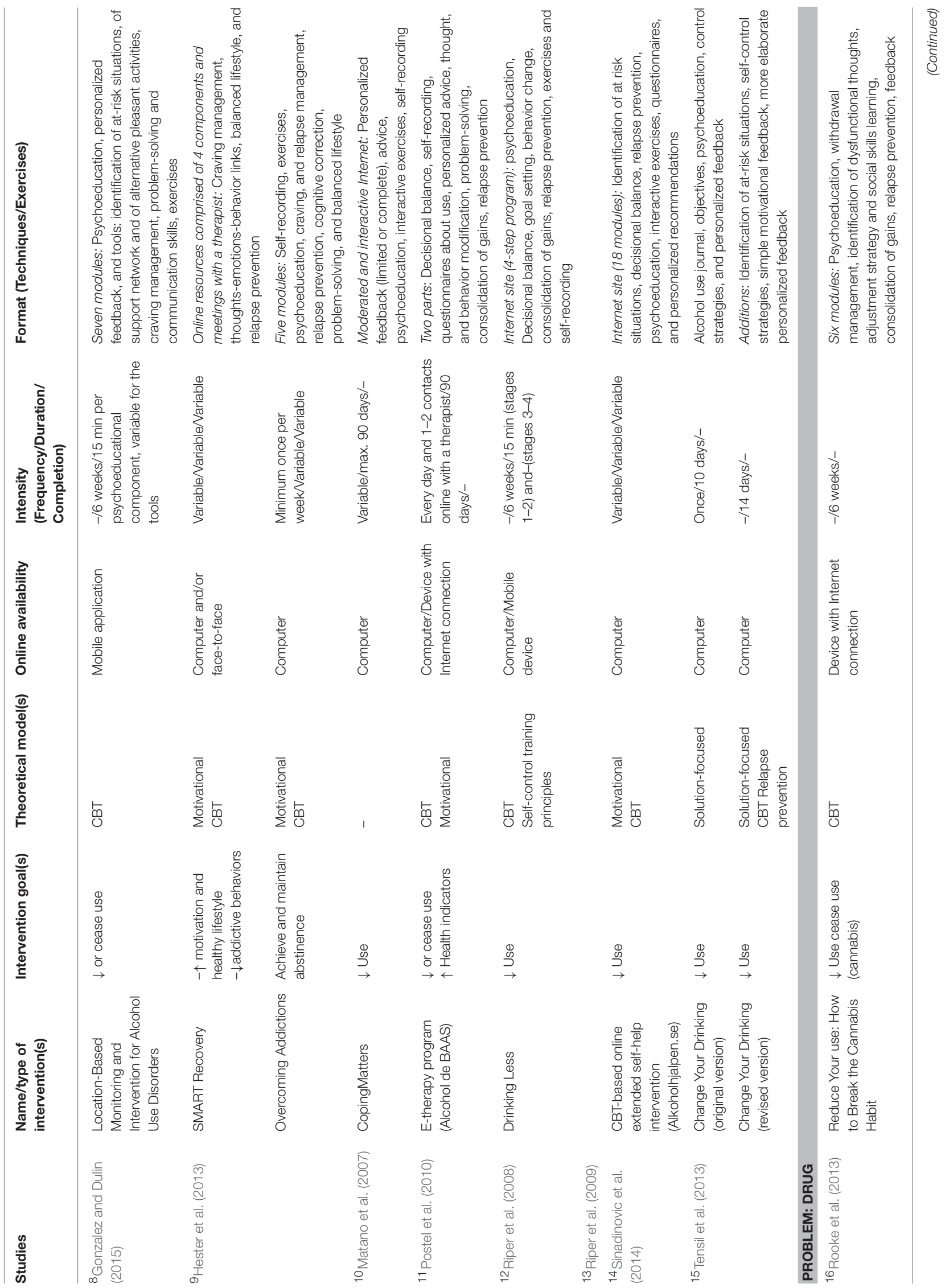




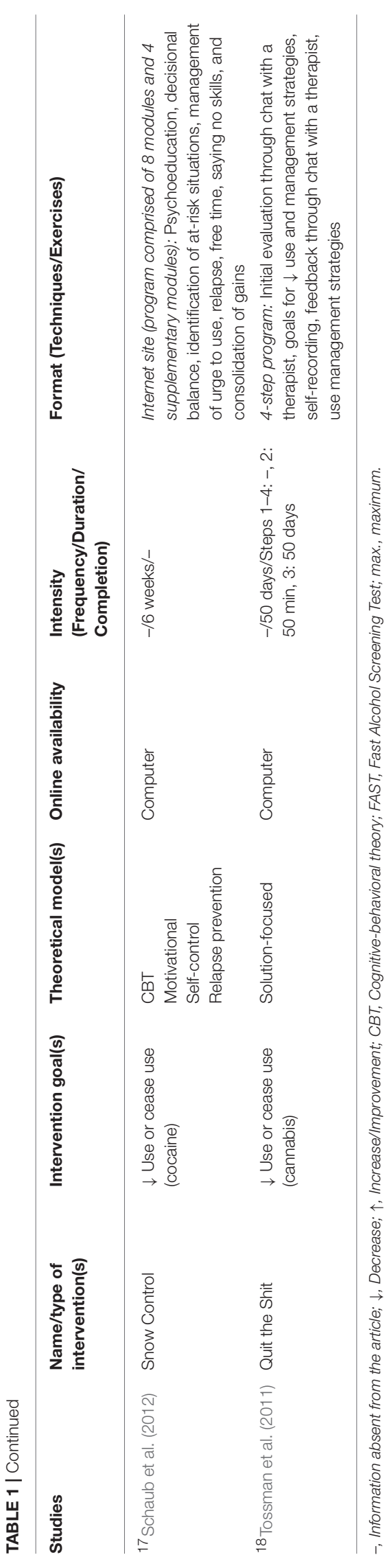

\section{Participants through Targeted Recruitment from a Population \\ University students ${ }^{2,5,7}$}

The participants were young adults, aged on average between $19^{5}$ and 25 years $^{7}$, studying full-time. Thirteen studies reported the sex of participants. Six reported an even distribution of men and women $(46.2 \% ; 1,8,11$ to 14$)$, however, a majority of men were found in six studies $(46.2 \% ; 3,6,15$ to 18 ), including the three studies evaluating a drug-related intervention. One study ${ }^{2}$ indicated that $4.6 \%$ of students received prior treatment and another ${ }^{7}$ showed at risk alcohol use among participants.

\section{Military personnel returning from combat ${ }^{4}$}

The participants were men (86\%) who had received a prior psychological treatment (61\%) and who presented problematic alcohol use.

\section{Workers from a targeted workplace ${ }^{10}$}

All the participants were employed, the majority were women (78\%) and had completed university studies (84\%).

\section{The Efficacy of Online Interventions}

Table 2 presents the efficacy of the interventions for bringing changes on at least one substance use indicator (i.e., frequency of use per week or month, amount of use per occasion).

\section{Short-Term Efficacy}

Fifteen of the 18 studies (83.3\%; 1 5, 7 to 11,14 to 18 ) evaluated post-intervention changes in substance use. These evaluations took place immediately after the intervention or within a delay varying between 2 weeks and 3 months after initial evaluation. The duration of the interventions being variable within a same study and between studies, the evaluation that takes place 3 months after initial evaluation could be considered close to the end of the intervention.

Eleven studies reported a significant decrease on at least one substance use indicator for the group receiving the online intervention, seven as compared to a control group without

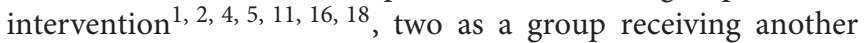
type of intervention ${ }^{8,10}$, and two without a control group 9,15 . However, four studies obtained mitigated results: a significant decrease in severity of alcohol related problems among all participants, including those in the group that received no intervention ${ }^{14}$, very limited efficacy ${ }^{17}$, or absence of efficacy ${ }^{3}$ as compared to a group without intervention, and even a lack of efficacy with an increase in substance use episodes among men $^{7}$.

\section{Medium and Long-Term Efficacy}

Eight of the 18 studies $(44.4 \% ; 1,3,5,6,12,13,14,17$ ) included a 6month post initial evaluation follow-up. Overall, these studies showed the maintenance of improvements observed shortly after intervention. Only two studies ${ }^{5,14}$ evaluated the maintenance of gains 12 months after the initial evaluation, of which one ${ }^{5}$ showed that the gains were maintained exclusively for women, whereas the other ${ }^{14}$ study showed maintenance of improvements for all groups, including the group who did not received intervention. 


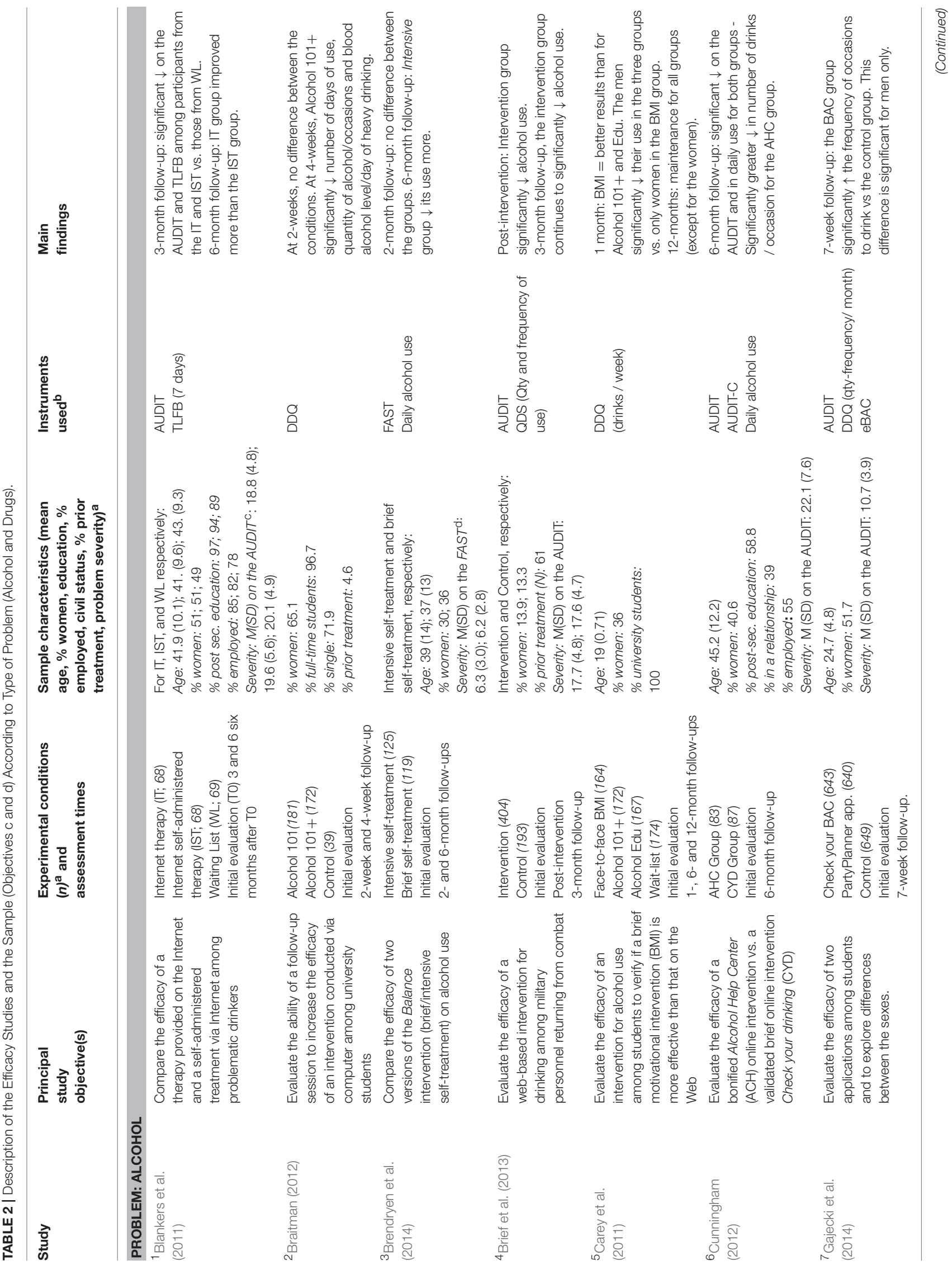




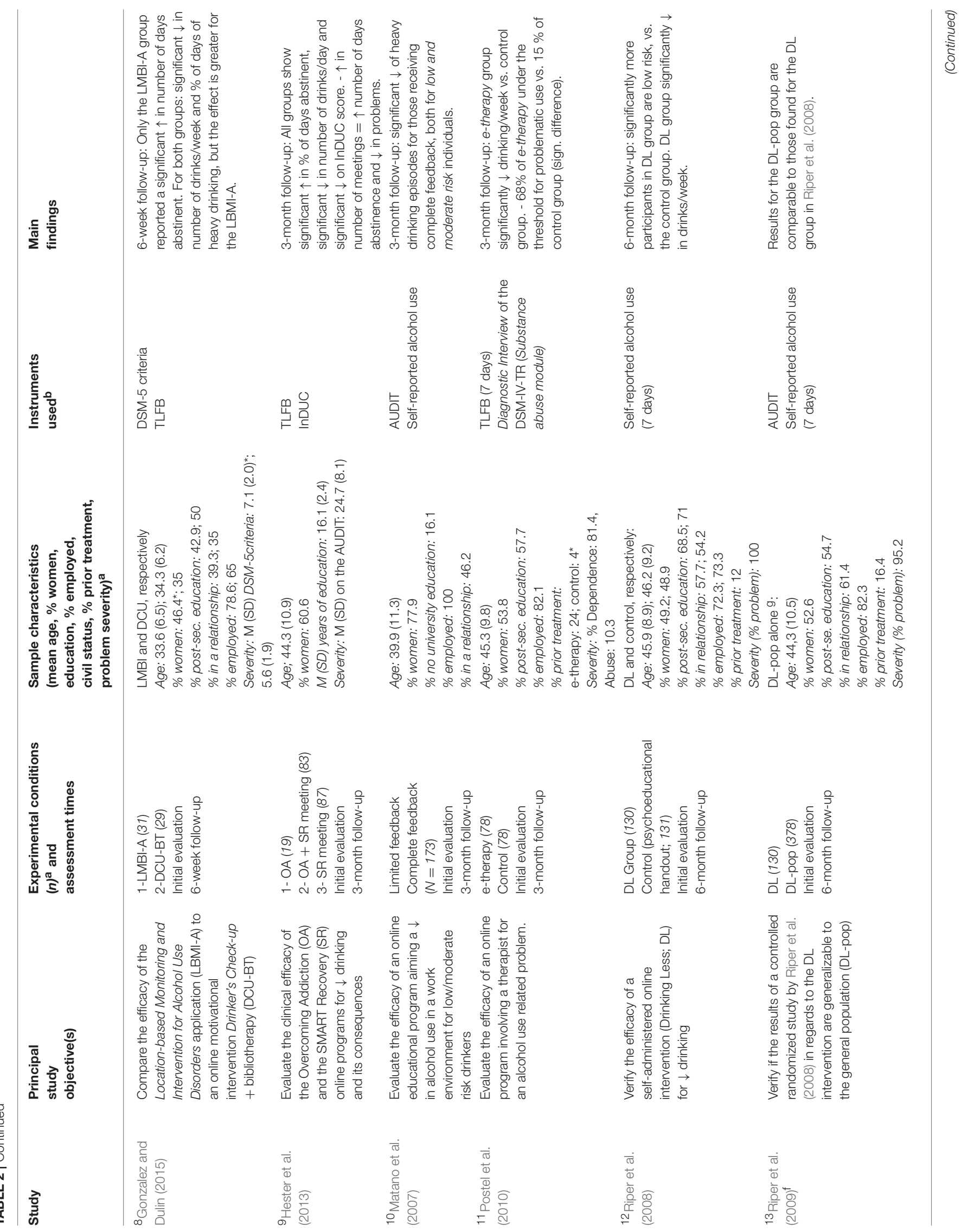




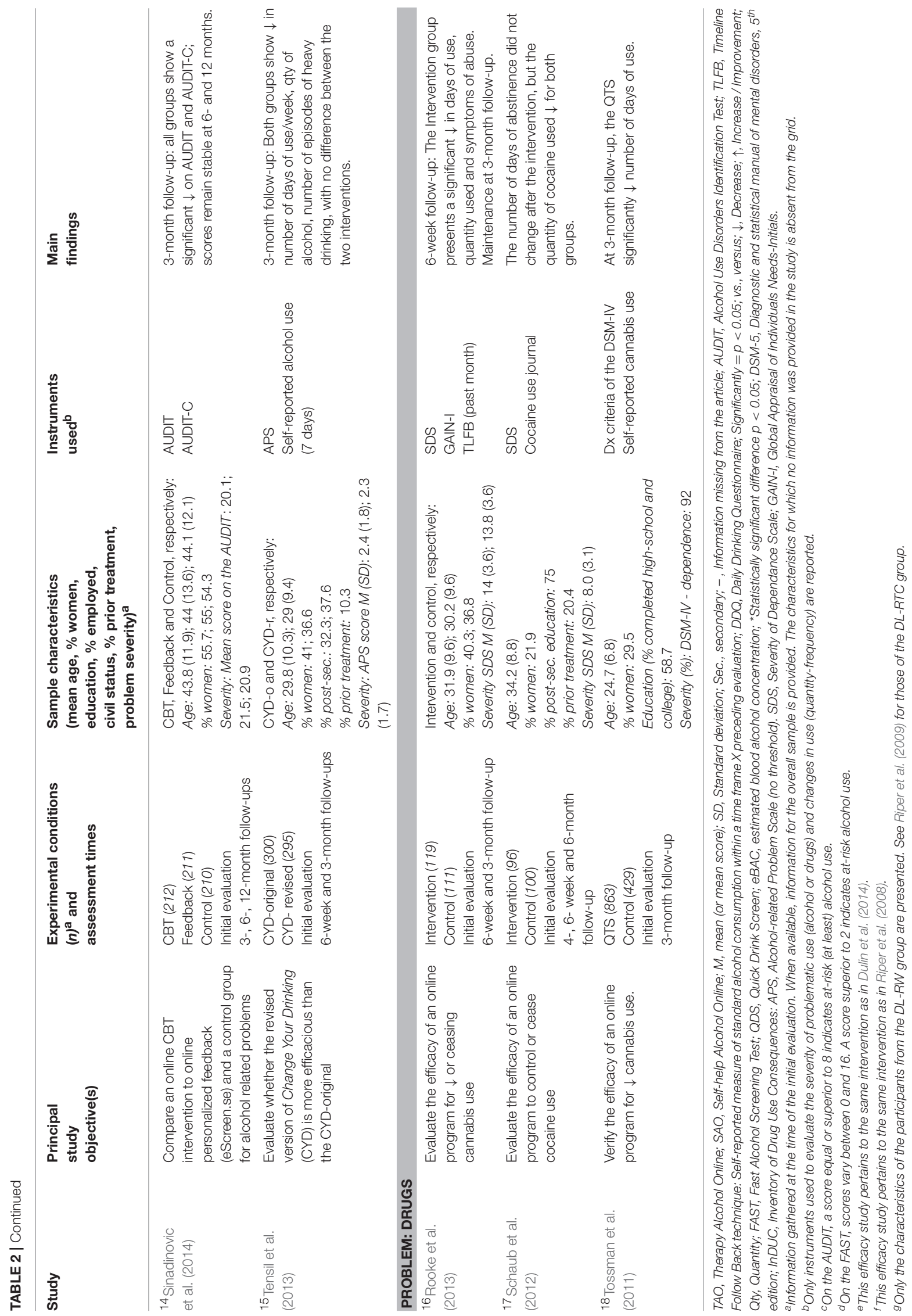




\section{Methodological Quality of the Studies}

Table 3 presents the evaluation of the studies based on the seven criteria in decreasing order of methodological quality score. Nine studies met six criteria (50\%; $4,6,7,9,14$ to 18 ), two satisfied five criteria $^{3,12}$, and six met four criteria ${ }^{1,2,8,10,11}$. One study met only two criteria $^{13}$. Half of the 18 studies $^{2,3}, 5,6,8,10,12,13,16$ presented insufficient information to determine if they met at least one criterion.

\section{DISCUSSION}

The goal of this systematic review is to portray psychological interventions that are entirely online for people with alcohol, drug, and gambling related problems.

Like the systematic review conducted by Danielsson et al. (2014), this review shows that studies evaluating the efficacy

TABLE 3 | Methodological Quality of the Studies According to Seven of the Eleven Criteria of the Cochrane Back Group Criteria List (objective e), According to Type of Problem (Alcohol and Drugs).

\begin{tabular}{|c|c|c|c|c|c|c|c|c|}
\hline \multirow[t]{2}{*}{ Study } & \multicolumn{8}{|c|}{ Criterion $^{a}$} \\
\hline & A & B & C & $\mathbf{H}$ & $\mathbf{I}$ & $\mathbf{J}$ & $\mathbf{K}$ & Total \\
\hline \multicolumn{9}{|l|}{ PROBLEM: ALCOHOL } \\
\hline${ }^{4}$ Brief et al. (2013) & + & + & + & + & - & + & + & 6 \\
\hline${ }^{6}$ Cunningham (2012) & + & + & + & $?$ & + & + & + & 6 \\
\hline${ }^{7}$ Gajecki et al. (2014) & + & + & + & + & - & + & + & 6 \\
\hline${ }^{9}$ Hester et al. (2013) & + & + & + & - & + & + & + & 6 \\
\hline${ }^{14}$ Sinadinovic et al. (2014) & + & + & + & + & - & + & + & 6 \\
\hline${ }^{15}$ Tensil et al. (2013) & + & + & + & + & - & + & + & 6 \\
\hline${ }^{3}$ Brendryen et al. (2014) & + & + & $?$ & + & - & + & + & 5 \\
\hline${ }^{12}$ Riper et al. (2008) & + & $?$ & + & + & - & + & + & 5 \\
\hline${ }^{1}$ Blankers et al. (2011) & + & + & + & - & - & - & + & 4 \\
\hline ²Braitman (2012) & + & + & $?$ & + & - & + & $?$ & 4 \\
\hline${ }^{5}$ Carey et al. (2011) & $?$ & $?$ & + & + & + & + & $?$ & 4 \\
\hline${ }^{8}$ Gonzalez and Dulin (2015) & - & - & + & + & + & + & $?$ & 4 \\
\hline${ }^{10}$ Matano et al. (2007) & + & $?$ & + & + & + & - & - & 4 \\
\hline${ }^{11}$ Postel et al. (2010) & + & + & + & + & - & - & + & 4 \\
\hline${ }^{13}$ Riper et al. (2009) & - & - & $?$ & + & - & - & + & 2 \\
\hline \multicolumn{9}{|l|}{ PROBLEM: DRUGS } \\
\hline${ }^{16}$ Rooke et al. (2013) & + & + & + & + & + & $?$ & + & 6 \\
\hline${ }^{17}$ Schaub et al. (2012) & + & + & + & + & - & + & + & 6 \\
\hline${ }^{18}$ Tossman et al. (2011) & + & + & + & + & - & + & + & 6 \\
\hline
\end{tabular}

+, Yes (criterion met); -, No (criterion not met); ?, Don't know (no indicator in the text making it possible to determine if the criterion is met).

Criterion A: Was the method of randomization adequate?

Criterion B: Was the treatment allocation concealed?

Criterion C: Were the groups similar at baseline regarding the most important prognostic indicators?

Criterion H: Was the compliance acceptable in all groups?

Criterion I: Was the dropout rate described and acceptable?

Criterion J: Was the timing of the outcome assessment in all groups similar?

Criterion K: Was the intent-to-treat analysis performed?

a The criteria D (Was the patient blinded to the intervention?), E (Was the care provider blinded to the intervention?), F (Was the outcome assessor blinded to the intervention?) and G (Were cointerventions avoided or similar?) were not evaluated because of difficulties applying them to the studies reviewed. of online interventions for alcohol related problems are more numerous than those for illegal drugs and gambling. Moreover, no efficacy study on a completely online intervention for problem gambling was retained for this study. With its systematic approach, this review highlights the glaring lack of research on the effectiveness of online or mobile applications to help individuals with gambling problems. Online interventions for gamblers were identified, but they were excluded for three main reasons. First, they targeted gambling prevention (personalized feedback) or addressed a student clientele without a gambling problem (for example, Hopper, 2008; Lostutter, 2009). Personalized feedback interventions are closer to secondary prevention than pure psychological intervention to reduce or eliminate an undesirable behavior (Hopper, 2008; Palfai et al., 2014). For the most part, these interventions do not target a specific clientele, as they include non-consumers with highrisk consumers (for example, Cunningham et al., 2006; Doumas and Andersen, 2009; Bewick et al., 2010; Labrie et al., 2013), with the goal to keep their consumption within recommended limits. Nevertheless, these personalized feedback interventions represent an innovative way of raising awareness about the participants' own consumption and may in some cases lead to changes in behavior. Second, these interventions were not offered completely online, as some studies included a telephone contact with a clinician (for example, Carlbring and Smit, 2008). Third, they did not present data about efficacy, like the preliminary study of satisfaction with an entirely online intervention for excessive gambling (see Zermatten et al., 2010). It would be important to prioritize to research into the use of new technologies in the treatment of problem gamblers, considering that standard "offline" self-help treatment programs are effective in reducing negative consequences of excessive gambling behavior (Hodgins et al., 2001, 2009; Giroux et al., 2015), but may not be easily accessible to gamblers. It thus appears necessary to empirically evaluate the efficacy of online interventions dedicated to problem gamblers.

The large majority of online interventions for alcohol or drugs were delivered on a web platform, with the exception of three mobile applications. Two of these applications (see Gajecki et al., 2014) differ from the other interventions in regards to their theoretical approach, that of planned behavior (Ajzen, 1991), and their content, which consisted of a behavioral tool to manage alcohol use and estimate blood alcohol levels in real time. Such interventions show that technological advances can potentially diversify intervention tools for users. Yet, as the review suggests, these interventions may lead to undesirable effects such as an increase in substance use occasions. These findings support the need to rigorously evaluate their efficacy and to require the same quality standards as for face-to- face treatments.

In regards to the therapeutic objectives targeted by online interventions, the majority of them offer a freedom of choice to the users as to goals of decreasing use or abstinence. They also offer users flexibility when targeting goals for decreased alcohol/drug use. Imposing abstinence may discourage many users from seeking assistance (Ursúa, 2008) and favor treatment withdrawal, even before treatment begins (Andrewartha and Dowling, 2006). The flexibility offered by online interventions 
may favor treatment adherence and even lead to a change of therapeutic objective toward abstinence, as observed in a large portion of the sample of gamblers receiving face-to-face treatment in the study conducted by Ladouceur et al. (2009).

The majority of online interventions are based on cognitive-behavioral or motivational approaches; approaches underpinning standard and self-administered psychological treatments for gambling and alcohol/drug related problems (Dutra et al., 2008; Cowlishaw et al., 2012; Martin and Rehm, 2012). These two approaches are recognized as efficient for addiction treatment and their structure, as well as the techniques used, appear to be easily adaptable to an online format (Gainsbury and Blaszczynski, 2011). This review suggests that for several interventions, the full potential of a web platform does not appear to be exploited. Indeed, with the exception of only a few interventions, the techniques and tools used appear to be mostly replicas of what is already offered offline. Only $18.2 \%$ of the interventions used an online chat room, while $4.5 \%$ offered an online support forum; these tools are very easy to set up, but the content needs to be supervised by a professional. As for mobile application interventions, they tend to exploit the originality of new technologies but may possibly lead to undesirable effects among certain participants; for example, an increase in use in order to use the mobile application more frequently, to see how much their blood alcohol level could rise. Rethinking the way these apps are engineered could help with this novelty effect.

Contrary to standard cognitive-behavioral treatments that give priority to a clear therapeutic framework (Andersson et al., 2016), this review shows that the suggested utilization of the online interventions for participants is variable, or even provided without any defined indicators. The flexibility of the therapeutic framework is typical of self-administered interventions, although those offered offline generally suggest a certain treatment intensity (Simoneau et al., 2004; for example, Carroll et al., 2008; Ladouceur et al., 2015). The malleable and little demanding framework of online interventions may counterbalance obstacles to entering treatment (Priester et al., 2016), but is susceptible to give rise to variable commitment and utilization.

This review made it possible to extract a profile of participants of online interventions for drug and alcohol use outside of targeted recruitment. Overall, the participants are mostly adults between 30 and 46 years old who are educated and employed. Although less than a quarter of the clientele reported having previously consulted for drug or alcohol related problems, the majority was identified as presenting problematic drug/alcohol use.

This profile appears similar to that drawn by Postel et al. (2011). The online format attracts adults between 30 and 46 years old, which indicates that this clientele may be more receptive to technological advances because of their active and regular Internet use (Ducharme, 2015). Users who utilize online interventions generally appear to be educated. This is consistent with the proposed type of interventions, which require reading, writing, and computer skills (Farrer et al., 2014). The high proportions of workers may also indicate that the flexibility offered by online interventions fits well within a busy life schedule. Studies show that a higher level of education (Spek et al., 2008) and being employed (de Graaf et al., 2010) are predictors of success on online cognitivebehavioral interventions for depression. The same may apply to interventions for drug and alcohol users, but further studies would be needed to verify this hypothesis. Finally, the fact that few participants had previously consulted suggests that online interventions are attractive for first time consultations; they may demystify treatment and act as a stepping stone toward other more intensive intervention modalities (Bower and Gilbody, 2005).

The online interventions generally seem to be efficacious for reducing certain drug and alcohol use behaviors on a short-term basis. The majority of the studies report positive results on at least one substance use indicator following intervention, and some show a medium term maintenance of gains. These results appear to be coherent with other studies evaluating the efficacy of offline self-help treatments (Hodgins et al., 2009; Giroux et al., 2015). However, few studies in the review evaluate long-term changes and those that do, report little conclusive findings. It thus remains difficult to draw conclusions about the long-term benefits of online interventions for problematic use of drugs/alcohol. These results point to the relevance of including longer-term follow-ups to verify the maintenance of gains over time.

This review presents some limitations. One of them relates to the difficulty of the review to meet the final research objective, that of presenting the methodological quality of the studies. Indeed, even though this grid used Cochrane recommended criteria, the evaluation grid used required the withdrawal of nearly a third of the tool's criteria because of the difficulty applying them to the types of studies identified. Another limitation relates to the subjective portrait offered by the review regarding the efficacy of the online interventions since the review's inclusion criteria, as well as the study objectives, did not make it possible to conduct a meta-analysis.

The review does however possess strengths, notably the scientific rigor employed during the study selection and database extraction processes. A second strength lays in the selection of interventions included in the review; those available entirely online. By differing from the review of Danielsson et al. (2014) that included different intervention modalities, alone or in combination, the present review draws a more homogenous portrait. However, the studies evaluating online interventions for problem gamblers were excluded and the conclusions offered cannot be generalized to this population. To draw a portrait of the users recruited from the general population represents another strength of the review, in that it provides support to empirical studies that have already conducted this exercise and makes it possible to identify the clientele that may be attracted to these online interventions.

In conclusion, this review shows that, in general, psychological interventions offered completely online for alcohol and drugs do not reinvent the underpinnings of self-administered interventions in regards to both the theoretical approach and their content. The online format represents an alternative way to offer these interventions, which could increase accessibility and attract a clientele who would not consult otherwise. These 
interventions appear promising and have short-term benefits among their users. However, further research is essential. Firstly, it is primordial to evaluate the efficacy of these interventions while including long-term follow-up measures. Secondly, the interventions offered through mobile applications appear to represent a challenge; they are based on less conventional approaches in regards to addiction and show mitigated results. This type of intervention should be further examined in order to ensure their safety. As such, other rigorous scientific studies are needed to be conducted before integrating them into a treatment program. Finally, development and evaluation of interventions that are entirely online for problem gambling are necessary steps to the diversification of intervention tools for this clientele.

\section{AUTHOR CONTRIBUTIONS}

Manuscript was written by IG, AG, JM, CJ, and SB. JM and SB helped with the study design, methodological issues and manuscript revision. Data were collected by AG and JM. The study and the manuscript redaction were supervised by IG. All authors made substantial contributions to the conception or design of the work; or the acquisition, analysis, or interpretation of data for the work; All authors worked on drafting the work or revising it critically for important intellectual content; and all authors approved the version to be published and agreed to be accountable for all aspects of the work in ensuring that questions related to the accuracy or integrity of any part of the work are appropriately investigated and resolved.

\section{FUNDING}

This study was funded by the Fonds de recherche du QuébecSociété et Culture in partnership with the ministère de la Santé et des Services sociaux du Québec \#2015-JU-181605.

\section{ACKNOWLEDGMENTS}

The authors thank Pierre-Yves Bergeron, Catherine Boudreault, Maxime Chrétien, Bianca Demers, Daniel Fortin-Guichard, Étienne Gagnon, Alexandre Hamel, Dominic Nadeau, and Mirjana Vucetic for their contribution to the study.

\section{REFERENCES}

Ajzen, I. (1991).The theory of planned behavior. Organ. Behav. Hum. Decis. Process. 50, 179-211. doi: 10.1016/0749-5978(91)90020-T

American Psychiatric Association (2013). Diagnostic and Statistical Manual of Mental Disorders, 5th Edn. Washington, DC: American Psychiatric Association.

Andersson, G., Carlbring, P., and Lindefors, N. (2016). "History and current status of ICBT," in Guided Internet-Based Treatments in Psychiatry, eds N. Lindefors and G. Andersson (New York, NY: Springer), 1-16.

Andrewartha, L., and Dowling, N. (2006). "Pre-treatment attrition for problem gambling," in Psychology Bridging the Tasman: Science, Culture and Practice, ed M. Katsikitis (Sydney, NSW: Australian Psychological Society), $16-20$.

Barak, A., Hen, L., Boniel-Nissim, M., and Shapira, N. (2008). A comprehensive review and a meta-analysis of the effectiveness of Internet-based psychotherapeutic interventions. J. Technol. Hum. Serv. 26, 109-160. doi: 10.1080/15228830802094429

Berger, V. W., and Alperson, S. Y. (2009). A general framework for the evaluation of clinical trial quality. Rev. Recent Clin. Trials 4, 79-88. doi: 10.2174/157488709788186021

Bewick, B. M., West, R., Gill, J., O’May, F., Mulhern, B., Barkham, M., et al. (2010). Providing web-based feedback and social norms information to reduce student alcohol intake: a multisite investigation. J. Med. Internet Res. 12:e59. doi: 10.2196/jmir.1461

Blankers, M., Koeter, M. W. J., and Schippers, G. M. (2011). Internet therapy versus internet self-help versus no treatment for problematic alcohol use: a randomized controlled trial. J. Consult. Clin. Psychol. 79, 330-341. doi: $10.1037 / \mathrm{a} 0023498$

Bower, P., and Gilbody, S. (2005). Stepped care in psychological therapies: access, effectiveness and efficiency: narrative literature review. Br. J. Psychiatry 186, 11-17. doi: 10.1192/bjp.186.1.11

Braitman, A. L. (2012). The Effects of Personalized Boosters for a Computerized Intervention Targeting College Student Drinking. Doctoral dissertation. Available from ProQuest Dissertations and Theses database (UMI No. 3510998).

Brendryen, H., Lund, I. O., Johansen, A. B., Riksheim, M., Nesvag, S., and Duckert, F. (2014). Balance-a pragmatic randomized controlled trial of an online intensive self-help alcohol intervention. Addiction 109, 218-226 doi: 10.1111 /add. 12383

Brief, D. J., Rubin, A., Keane, T. M., Enggasser, J. L., Roy, M., Helmuth, E., et al. (2013). Web intervention for OEF/OIF veterans with problem drinking and PTSD symptoms: a randomized clinical trial. J. Consult. Clin. Psychol. 81, 890-900. doi: 10.1037/a0033697

Calado, F., and Griffiths, M. D. (2016). Problem gambling worldwide: an update and systematic review of empirical research (2000-2015). J. Behav. Addict. 5, 592-613. doi: 10.1556/2006.5.2016.073

Carey, K. B., Carey, M. P., Henson, J. M., Maisto, S. A., and Demartini, K. S. (2011). Brief alcohol interventions for mandated college students: comparison of face-to-face counseling and computer-delivered interventions. Addiction 106, 528-537. doi: 10.1111/j.1360-0443.2010.03193.x

Carlbring, P., and Smit, F. (2008). Randomized trial of internet-delivered self-help with telephone support for pathological gamblers. J. Consult. Clin. Psychol. 76, 1090-1094. doi: 10.1037/a0013603

Carroll, K. M., Ball, S. A., Martino, S., Nich, C., Babuscio, T. A., Nuro, K. F., et al. (2008). Computer-assisted delivery of cognitive-behavioral therapy for addiction: a randomized trial of CBT4CBT. Am. J. Psychiatry 165, 881-888. doi: 10.1176/appi.ajp.2008.07111835

Childress, C. A., and Asamen, J. K. (1998). The emerging relationship of psychology and the Internet: proposed guidelines for conducting Internet intervention. Res. Ethics Behav. 8, 19-35. doi: 10.1207/s15327019eb0801_2

Clarke, D. (2007). Intrinsic and extrinsic barriers to health care: implications for problem gambling. Int. J. Ment. Health Addict. 5, 279-291. doi: 10.1007/s11469-007-9089-1

Cowlishaw, S., Merkouris, S., Dowling, N., Anderson, C., Jackson, A., and Thomas, S. (2012). Psychological therapies for pathological and problem gambling. Cochrane Libr. 11, 1-73. doi: 10.1002/14651858.cd008937.pub2

Cunningham, J. A. (2012). Comparison of two Internet-based interventions for problem drinkers: randomized controlled trial. J. Med. Internet Res. 14, 24-30. doi: 10.2196/jmir.2090

Cunningham, J. A., and Brelin, F. C. (2004). Only one on three people with alcohol abuse or dependence ever seek treatment. Addict. Behav. 29, 221-223. doi: 10.1016/S0306-4603(03)00077-7

Cunningham, J. A., Humphreys, K., Kypri, K., and van Mierlo, T. (2006). Formative evaluation and three-month follow-up of an online personalized assessment feedback intervention for problem drinkers. J. Med. Internet Res. 8:e5. doi: 10.2196/jmir.8.2.e5

Cunningham, J. A., Wild, T. C., and Humphreys, K. (2011). Who uses online interventions for problem drinkers? J. Subst. Abuse Treat. 41, 261-264. doi: 10.1016/j.jsat.2011.03.003 
Danielsson, A.-K., Eriksson, A.-K., and Allebeck, P. (2014). Technologybased support via telephone or web: a systematic review of the effects on smoking, alcohol use and gambling. Addict. Behav. 39, 1846-1868. doi: 10.1016/j.addbeh.2014.06.007

de Graaf, L. E., Hollon, S. D., and Huibers, M. J. H. (2010). Predicting outcome in computerized cognitive behavioral therapy for depression in primary care: a randomized trial. J. Consult. Clin. Psychol. 78, 184-189. doi: 10.1037/a0018324

Doumas, D. M., and Andersen, L. L. (2009). Reducing alcohol use in first-year university students: evaluation of a web-based personalized feedback program. J. College Counsel. 12, 18-32. doi: 10.1002/j.2161-1882.2009.tb00037.x

Ducharme, G. (2015). L'État du Québec Numérique en 2015: des Québécois très Branchés, Mobiles et Actifs sur les Réseaux Sociaux [The State of Digital Quebec in 2015: Quebecers that are Very Connected, Mobile and Active on Social Networks]. Cefrio, l'Expérience du Numérique. Available online at: http://www.cefrio.qc.ca/netendances/equipement-branchement-2013/

Dulin, P. L., Gonzalez, V. M., and Campbell, K. (2014). Results of a pilot test of a self-administered smartphone-based treatment system for alcohol use disorders: usability and early outcomes. Subst. Abus. 35, 168-175. doi: 10.1080/08897077.2013.821437

Dutra, L., Stathopoulou, G., Basden, S. L., Leyro, T. M., Powers, M. B., and Otto, M. W. (2008). A meta-analytic review of psychosocial interventions for substance use disorders. Am. J. Psychiatry 165, 179-187. doi: 10.1176/appi.ajp.2007.06111851

Farrer, L. M., Griffiths, K. M., Christensen, H., Mackinnon, A. J., and Batterham, P. J. (2014). Predictors of adherence and outcome in internet-based cognitive behavior therapy delivered in a telephone counseling setting. Cognit. Ther. Res. 38, 358-367. doi: 10.1007/s10608-013-9589-1

Gainsbury, S., and Blaszczynski, A. (2011). A systematic review of Internetbased therapy for the treatment of addictions. Clin. Psychol. Rev. 31, 490-498. doi: 10.1016/j.cpr.2010.11.007

Gajecki, M., Berman, A. H., Sinadinovic, K., Rosendahl, I., and Andersson, C. (2014). Mobile phone brief intervention applications for risky alcohol use among university students: a randomized controlled study. Addict. Sci. Clin. Pract. 9, 1-12. doi: 10.1186/1940-0640-9-11

Giroux, I., Boudreault, C., Faucher-Gravel, A., Goulet, A., Ladouceur, R., Simoneau, H., et al. (2015). JEu Me Questionne: Bonification et Validation Scientifique [JEu me Questionne: Scientific Upgrade and Validation]. Québec, QC: Université Laval.

Gonzalez, V. M., and Dulin, P. L. (2015). Comparison of a smartphone app for alcohol use disorders with an Internet-based intervention plus bibliotherapy: a pilot study. J. Consult. Clin. Psychol. 83, 335-345. doi: 10.1037/a0038620

Gooding, P., and Tarrier, N. (2009). A systematic and meta-analysis of cognitivebehavioural interventions to reduce problem gambling: hedging our bets? Behav. Res. Ther. 47, 592-607. doi: 10.1016/j.brat.2009.04.002

Hester, R. K., Lenberg, K. L., Campbell, W., and Delaney, H. D. (2013). Overcoming addictions, a Web-based application, and SMART recovery, an online and in-person mutual help group for problem drinkers, part 1: threemonth outcomes of a randomized controlled trial. J. Med. Internet Res. 15:e134. doi: 10.2196/jmir.2565

Hodgins, D. C., Currie, S. R., Currie, G., and Fick, G. H. (2009). Randomized trial of brief motivational treatments for pathological gamblers: more is not necessarily better. J. Consult. Clin. Psychol. 77, 950-960. doi: 10.1037/a0016318

Hodgins, D. C., Currie, S. R., and El-Guebaly, N. (2001). Motivational enhancement and self-help treatments for problem gambling. J. Consult. Clin. Psychol. 69, 50-57. doi: 10.1037/0022-006X.69.1.50

Hopper, R. A. H. (2008). A Brief Electronic Personalized Normative Feedback Intervention for the Prevention of Problematic Gambling among College Students. Doctoral dissertation. Available from: ProQuest Dissertation and Theses database (UMI No. 3324557).

Labrie, J. W., Lewis, M. A., Atkins, D. C., Neighbors, C., Zheng, C., Kenney, S. R., et al. (2013). RCT of web-based personalized normative feedback for college drinking prevention: are typical student norms good enough? J. Consult. Clin. Psychol. 81, 1074-1086. doi: 10.1037/a0034087

Labrie, R. A., Peller, A. J., LaPlante, D. A., Bernard, B., Harper, A., Schrier, T., et al. (2012). A brief self-help toolkit intervention for gambling problems: a randomized multisite trial. Am. J. Orthopsychiatry 82, 278-289. doi: 10.1111/j.1939-0025.2012.01157.x
Ladouceur, R., Fournier, P.-M., Lafond, S., Boudreault, C., Goulet, A., Sévigny, S., et al. (2015). Impacts of a self-help treatment program for problem gamblers. Can. J. Addict. 6, 37-44.

Ladouceur, R., Lachance, S., and Fournier, P.-M. (2009). Is control a viable goal in the treatment of pathological gambling? Behav. Res. Ther. 47, 189-197. doi: 10.1016/j.brat.2008.11.004

Lal, S., and Adair, C. E. (2014). E-mental health: a rapid review of the literature. Psychiatr. Serv. 65, 24-32. doi: 10.1176/appi.ps.201300009

Lombard, M., Snyder-Duchm, J., and Bracken, C. C. (2002). Content analysis in mass communication: assessment and reporting of intercoder reliability. Hum. Commun. Res. 28, 587-604. doi: 10.1111/j.1468-2958.2002. tb00826.x

Lostutter, T. W. (2009). A Randomized Clinical Trial of a Web-Based Prevention Program for At-Risk Gambling College Student. Doctoral dissertation. Available from ProQuest Dissertation and Theses database (UMI No. 3377255).

Magill, M., and Ray, L. A. (2009). Cognitive-behavioral treatment with adult alcohol and illicit drugs users: a meta-analysis of randomized controlled trials. J. Stud. Alcohol Drugs 70, 516-527. doi: 10.15288/jsad.2009.70.516

Mains, J. A., and Scogin, F. R. (2003). The effectiveness of self-administered treatments: a practice-friendly review of the research. J. Clin. Psychol. 59, 237-246. doi: 10.1002/jclp.10145

Martin, G. W., and Rehm, J. (2012). The effectiveness of psychosocial modalities in the treatment of alcohol problems in adults: a review of the evidence. Can. J. Psychiatry 57, 350-358. doi: 10.1177/070674371205700604

Matano, R. A., Koopman, C., Wanat, S. F., Winzelberg, A. J., Whitsell, S. D., Westrup, D., et al. (2007). A pilot study of an interactive web site in the workplace for reducing alcohol consumption. J. Subst. Abuse Treat. 32, 71-80. doi: 10.1016/j.jsat.2006.05.020

McKellar, J., Austin, J., and Moos, R. (2012). Building the first step: a review of low-intensity interventions for stepped care. Addict. Sci. Clin. Pract. 7, 1-14. doi: 10.1186/1940-0640-7-26

Musiat, P. G., and Tarrier, N. (2014). Collateral outcomes in e-mental health: a systematic review of the evidence for added benefits of computerized cognitive behavior therapy interventions for mental health. Psychol. Med. 44, 3137-3150. doi: 10.1017/S0033291714000245

Newman, M. G., Szkodny, L. E., Llera, S. J., and Przeworski, A. (2011). A review of technology-assisted self-help and minimal contact therapies for drug and alcohol abuse and smoking addiction: is human contact necessary for therapeutic efficacy? Clin. Psychol. Rev. 31, 178-186. doi: 10.1016/j.cpr.2010.10.002

Palfai, T. P., Winter, M., Lu, J., Rosenbloom, D., and Saitz, R. (2014). Personalized feedback as a universal prevention approach for college drinking: a randomized trial of an e-mail linked universal web-based alcohol intervention. J. Prim. Prev. 35, 75-84. doi: 10.1007/s10935-013-0337-9

Pallesen, S., Mitsem, M., Kvale, G., Johnsen, B.-H., and Molde, H. (2005). Outcome of psychological treatments of pathological gambling: a review and meta-analysis. Addiction 100, 1412-1422. doi: 10.1111/j.1360-0443.2005. 01204.x

Postel, M. G., de Haan, H. A., Huurne, E. D., Becker, E. S., and Jong, C. A. J. (2010). Effectiveness of a web-based intervention for problem drinkers and reasons for dropout: randomized controlled trial. J. Med. Internet Res. 12, 11-22. doi: 10.2196/jmir.1642

Postel, M. G., de Haan, H. A., Ter Huurne, E. D., Becker, E. S., and de Jong, C. A. J. (2011). Characteristics of problem drinkers in e-therapy versus face-to-face treatment. Am. J. Drug Alcohol Abuse 37, 537-542. doi: 10.3109/00952990.2011.600388

Priester, M. A., Browne, T., Iachini, A., Clone, S., DeHart, D., and Seay, K. D. (2016). Treatment access barriers and disparities among individuals with co-occurring mental health and substance use disorders: an integrative literature review. J. Subst. Abuse Treat. 61, 47-59. doi: 10.1016/j.jsat.2015. 09.006

Riper, H., Kramer, J., Conijn, B., Smith, F., Schippers, G., and Cuijpers, P. (2009). Translating effective web-based self-help for problem drinking into the real world. Alcohol. Clin. Exp. Res. 33, 1401-1407. doi: 10.1111/j.1530-0277.2009.00970.x

Riper, H., Kramer, J., Smit, F., Conijn, B., Schippers, G., and Cuijpers, P. (2008). Web-based self-help for problem drinkers: a pragmatic 
randomized trial. Addiction 103, 218-227. doi: 10.1111/j.1360-0443.2007. 02063.x

Rockloff, M., and Schofield, G. (2004). Factor analysis of barriers to treatment for problem gambling. J. Gambl. Stud. 20, 121-126. doi: 10.1023/B:JOGS.0000022305.01606.da

Rooke, S., J., Copeland, Norberg, M., Hine, D., and McCambridge, J. (2013). Effectiveness of a self-guided web-based cannabis treatment program: randomized controlled trial. J. Med. Internet Res. 15:e26. doi: 10.2196/jmir.2256

Sacks, J. J., Gonzales, K. R., Bouchery, E. E., Tomedi, L. E., and Brewer, R. D. (2015). 2010 National and state costs of excessive alcohol consumption. Am. J. Prev. Med. 49, e73-e79. doi: 10.1016/j.amepre.2015.05.031

Schaub, M., Sullivan, R., Haug, S., and Stark, L. (2012). Web-based cognitive behavioral self-help intervention to reduce cocaine consumption in problematic cocaine users: randomized controlled trial. J. Med. Internet Res. 14, 47-60. doi: 10.2196/jmir.2244

Schmidt, U., and Wykes, T. (2012). E-mental health-a land of unlimited possibilities. J. Ment. Health 21, 327-331. doi: 10.3109/09638237.2012.705930

Simoneau, H., Landry, M., and Tremblay, J. (2004). Alcochoix +, un Guide pour Choisir et Atteindre vos Objectifs [Alcochoice +, a Guide to Choosing and Reaching your Objectives]. Montreal, QC: RISQ.

Sinadinovic, K., Wennberg, P., Johansson, M., and Bermanm, A. H. (2014). Targeting individuals with problematic alcohol use via web-based cognitivebehavioral self-help modules, personalized screening feedback or assessment only: a randomized controlled trial. Eur. Addict. Res. 20, 305-318. doi: $10.1159 / 000362406$

Somers, J. M., Goldner, E. M., Waraich, P., and Hsu, L. (2004). Prevalence studies of substance-related disorders: a systematic review of the literature. Can. J. Psychiatry 49, 373-384. doi: 10.1177/070674370404900606

Spek, V., Nyklicek, I., Cuijpers, P., and Pop, V. (2008). Predictors of outcome of group and internet-based cognitive behavior therapy. J. Affect. Disord. 105, 137-145. doi: 10.1016/j.jad.2007.05.001

Suurvali, H., Cordingley, J., Hodgins, D. C., and Cunningham, J. (2009). Barriers to seeking help for gambling problem: a review of the empirical literature. J. Gambl. Stud. 25, 407-424. doi: 10.1007/s10899-009-9129-9

Suurvali, H., Hodgins, D., Toneatto, T., and Cunningham, J. A. (2008). Treatment seeking among Ontario problem gamblers: results of a population survey. Psychiatr. Serv. 59, 1343-1346. doi: 10.1176/ps.2008.59.11.1343
Swan, J. L., and Hodgins, D. C. (2015). Brief interventions for disordered gambling. Can. J. Addict. 6, 29-36.

Tait, R. J., and Christensen, H. (2010). Internet-based interventions for young people with problematic substance use: a systematic review. Med. J. Aust. 192, S15-S21.

Tait, R. J., Spijkerman, R., and Riper, H. (2013). Internet and computer based interventions for cannabis use: a meta-analysis. Drug Alcohol Depend. 30, 295-304. doi: 10.1016/j.drugalcdep.2013.05.012

Takano, A., Miyamoto, Y., and Matsumoto, T. (2015). [A review about new approaches using the Internet and computer technology for people with drug use disorder] [Abstract]. Nihon Arukoru Yakubutsu Igakkai Zasshi 50, 19-34.

Tensil, M.-D., Jonas, B., and Strüber, E. (2013). Two fully automated web-based interventions for risky alcohol use: randomized controlled trial. J. Med. Internet Res. 15, e110. doi: 10.2196/jmir.2489

Tossman, H.-P., Jonas, B., Tensil, M.-D., Lang, P., and Strüber, E. (2011). A controlled trial of an Internet-based intervention program for cannabis users. Cyperpsychol. Behav. Soc. Netw. 14, 673-679. doi: 10.1089/cyber. 2010.0506

Ursúa, M. P. (2008). Controlled gambling as a therapeutic option. J. Gambl. Issues $21,1-5$.

Zermatten, A., Jermann, F., Khazaal, Y., Zullino, D., and Bondolfi, G. (2010). Traiter l'addiction aux jeux de hasard et d'argent: un programme Internet [Treating gambling addiction: an Internet program]. Linform. Psychiatr. 86, 753-775. doi: 10.3917/inpsy.8609.0753

Conflict of Interest Statement: The authors declare that the research was conducted in the absence of any commercial or financial relationships that could be construed as a potential conflict of interest.

Copyright (c) 2017 Giroux, Goulet, Mercier, Jacques and Bouchard. This is an openaccess article distributed under the terms of the Creative Commons Attribution License (CC BY). The use, distribution or reproduction in other forums is permitted, provided the original author(s) or licensor are credited and that the original publication in this journal is cited, in accordance with accepted academic practice. No use, distribution or reproduction is permitted which does not comply with these terms. 